\title{
ELECTRONIC AIDS TO THE IDENTIFICATION OF BATS IN FLIGHT AND TO THEIR STUDY UNDER NATURAL CONDITIONS
}

\author{
by
}

\author{
ANDREW WATSON \\ 35, Richmond Road, Basingstoke, Hants., Great Britain
}

Positive identification of bats usually requires visual inspection at close range or for a bat to be held in the hand. There are many people, particularly conservationists, who would like to study bats in their natural environment without disturbing them.

The task of preparing distribution maps is at present a slow and painstaking task, depending on the limited number of observers who can accurately identify bats. Most bats emerge at dusk and although some can be seen in such poor lighting conditions, most bats flying at night cannot be observed when below the horizon and against a dark background.

A useful purpose may be served if electronic equipment can be devised which is comparatively inexpensive and which will yet enable the amateur naturalist to detect the presence of bats, provide him with useful factors to assist with the problem of identifying bats in flight and enable him to watch bats behaving naturally in complete darkness.

Conversion of ultrasounds to audible signals is described in relation to the problem of discrimination between species, experiments in detecting wing beat in flying bats using portable radar are mentioned and also the application of night vision devices to bat watching.

\section{CONVERSION OF ULTRASOUNDS}

Conversion of the ultrasounds of bats into audible signals can serve several useful purposes:

(a) Detection of the presence of some species. - All bat species occurring in Britain emit ultrasounds when awake and orienting themselves in the roost. When flying, ultrasounds are emitted for the purposes of navigation, locating and homing on prey.

(b) Some information on feeding. - As ves- pertilionid bats close in on their prey in flight the number of echolocation "shouts" increases and this can be heard as an audible "burp" when converted to an audible signal.

(c) Additional factors to assist in the identification of some species are provided by the converted ultrasounds.

Although this has been dealt with elsewhere (Watson, 1965) the following paragraphs summarize the situation.

\section{HOLGATE ULTRASONIC RECEIVER}

A group of British bat experts prepared a specification from which the Holgate ultrasonic receiver was developed by Holgates of Totton Ltd., Totton, Hants. A condenser microphone sensitive in the $10-150 \mathrm{kHz}$ band collects the ultrasounds which are then amplified and converted into audible signals.

Bats emitting constant frequency pulses (Rhinolophidae) are heterodyned. The luwer end of the swept frequency pulses of a few of the species occurring in Britain can also be heterodyned (e.g. Pipistrellus pipistrellus, Nyctalus noctula, $N$. leisle$r i_{i}$ and Eptesicus serotinus) at certain frequencies. Tuning across the swept frequencies of all vespertilionid bats produces clicks at various frequencies, and records are kept of the frequencies at which nothing is heard, or at which faint clicks or loud clicks are heard.

The resulting audible signals are characteristic for each species of bat, although there may be some variation due to equipment used by different field workers, distance of bat from microphone, etc. Tape recordings of the converted ultrasounds of bats are being fed into the British Library of Wildlife Sounds (BLows), 29, Exhibition Road, London S.W. 7, so that field workers can have 
Table I. A guide to the converted ultrasounds of bats for field work using the Holgate Ultrasonic Receiver

\begin{tabular}{ccc}
\hline Species & $\begin{array}{c}\text { Approx. } \\
\text { Recorded in } \\
\text { captivity in a distance at which for field work } \\
\text { room at range of: bat recorder in } \\
\text { flight in the field }\end{array}$ & $\begin{array}{c}\text { Approximate } \\
\text { frequency range Beat Frequency Oscillator (BFO) on }\end{array}$ \\
\hline
\end{tabular}

\begin{tabular}{|c|c|c|c|c|}
\hline Rhinolophus ferrumequinum & & $10 \mathrm{~m}$ & 82 & $\begin{array}{l}\text { Warbling at } \pm 1 \mathrm{KHz} \text { either side of } \\
82 \mathrm{KHz} \text {. }\end{array}$ \\
\hline Rhino!ophus hipposideros & $2 \mathrm{~m}$ & & \multicolumn{2}{|c|}{$\begin{array}{l}\text { May be heard on various constant frequencies from } \\
105-125 \mathrm{KHz} \text { as a warbling sound }\end{array}$} \\
\hline Pipistrellus pipistrellus & & $20 \mathrm{~m}$ & $35-110$ & $\begin{array}{l}\text { Tune to about } 48 \mathrm{KHz} \text { for a distinct } \\
\text { tweet heard only in flight }\end{array}$ \\
\hline Myotis myotis & $6 \mathrm{~m}$ & & $30-70$ & Loud sharp tick, not heard on $80 \mathrm{KHz}$ \\
\hline Myotis bechsteini & $2 \mathrm{~m}$ & & $40-120$ & Sharp tick, audible on $80 \mathrm{KHz}$ \\
\hline Myotis daubentoni & & $10 \mathrm{~m}$ & $25-80$ & Dull tick, loudest about $50 \mathrm{KHz}$ \\
\hline Myotis mystacinus & $3 \mathrm{~m}$ & & $35-80$ & $\begin{array}{l}\text { Faint or inaudible below } 35 \mathrm{KHz} \\
\text { Dull tick. }\end{array}$ \\
\hline Myotis nattereri & & $4 \mathrm{~m}$ & $40-110$ & $\begin{array}{l}\text { Faint below } 40 \mathrm{KHz} \text {. Sharp tick heard } \\
\text { from } 50-100 \mathrm{KHz} \text { with no maximum } \\
\text { point of loudness. }\end{array}$ \\
\hline Barbastella barbastellus & $3 \mathrm{~m}$ & & $30-80$ & $\begin{array}{l}\text { Sharp tick; slight beat at about } \\
52 \mathrm{KHz}\end{array}$ \\
\hline Eptesicus serotinus & & $40 \mathrm{~m}$ & $15-70$ & $\begin{array}{l}\text { Dull tock at about } 35 \mathrm{KHz} \text { and } \\
\text { tweets at about } 18 \mathrm{KHz}\end{array}$ \\
\hline $\begin{array}{l}\text { Nyctalus leisleri } \\
\text { Nyctalus noctula }\end{array}$ & & $\begin{array}{l}100 \mathrm{~m} \\
100 \mathrm{~m}\end{array}$ & $\begin{array}{l}15-70 \\
15-70\end{array}$ & $\begin{array}{l}\text { Tweets at } 18-20 \mathrm{KHz} \text { with a very } \\
\text { characteristic rhythm described as } \\
\text { "Tweet-chock, tweet, tweet-chock" }\end{array}$ \\
\hline Plecotus auritus & $1 \mathrm{~m}$ & & inaudible excep & at very close range \\
\hline Myotis dasycneme & $6 \mathrm{~m}$ & & $25-90$ & $\begin{array}{l}\text { Metallic chink heard at } 35 \mathrm{KHz} \\
\text { Dull tick between } 40-70 \mathrm{KHz}\end{array}$ \\
\hline Myotis emarginatus & $5 \mathrm{~m}$ & & $30-100$ & $\begin{array}{l}\text { Thin tick throughout except from } \\
45-55 \mathrm{KHz} \text { approx. when dull tick }\end{array}$ \\
\hline
\end{tabular}

Notes:

1) If the Beat Frequency Oscillator is kept on then characteristic warbles and tweets will be heard if the ultrasounds emitted by the bat can be heterodyned. Ticks and tocks are the non-musical sounds that can be heard whether the BFO is on or off. A "tock" is, in effect, the result of hearing two clicks in quick succession.

2) The method used to obtain the information in the tabie was to tune through the full range of the Holgate ultrasonic receiver noting the highest and lowest freauencies at which bats could be detected in flight and at what frequencies, if any, musical notes (tweets or warbles) could be obtained with the BFO.

3) Some explanation of why converted ultrasounds sound the way they do can be obtained by a study of sonagrams. 
easy access to audio information for the comparison of results. A rough guide is given in table $I$. Factors in identification include the behaviour of individual species, time of emergence, audible sounds (including those heard by young people), height of flight, comparative size of bat and, of course, prior knowledge of the presence of a nursing colony nearby.

To these can be added the factor provided by the converted ultrasounds. When recording it is useful to tune through the whole of a bat's ultrasonic spectrum, recording the converted ultrasounds at 5 or $10 \mathrm{kHz}$ intervals. The lowest frequency at which a bat can be detected is a useful factor.

It is clear that certain species having apparent similar physical characteristics in common, also emit similar ultrasounds (e.g. Myotis myotis and $M$. bechsteini in the laboratory and Nyctalus noctula and $N$. leisleri in the field are typical "pairs" which may be difficult to tell apart although the former is, in each pair, the larger of the two species).

In instances where the size varies between different species which emit similar ultrasounds, other means must be found to discriminate between species. It is proposed to try to compare wing beat in bats by using portable radar, and the first attempts will be described later.

\section{HOME MADE ULTRASONIC RECEIVERS}

It is important that once an electronic device has been shown to be of some value to the amateur naturalist, that means should be devised for equipment to be available at comparatively low cost.

By enlisting the help of amateur radio enthusiasts it should be possible to build a useful bat detector fairly cheaply. A circuit recommended by Pye (1968) has been followed and satisfactory results are being obtained from a prototype unit built in a biscuit tin. The project is intended to encourage amateur naturalists to get local help in making similar instruments.

\section{MEASURING WING BEATS BY RADAR}

It may be useful to develop portable radar equipment which can provide an audible reflected signal from the wing beats of bats in flight.

Two small radar units have recently been evaluated. These are Doppler Radar Sensing Equipment MPS 1 made by Automation Techniques and Systems Ltd., Wolverhampton Airport, Eng- land, and the $3 \mathrm{~cm}$ transmitter and $3 \mathrm{~cm}$ receiver manufactured by O. \& R. Electronics Ltd., 5, Long Street, London E.1.

The MPS 1 is a $2 \mathrm{~cm}$ radar using a Gunn diode and mixer diode in a tuned cavity which is oblong in section. It is in two parts, the Head with its horn and a separate power supply and amplifier.

The $3 \mathrm{~cm}$ Transmitter uses a klystron in a tuned cavity, and can emit either a CW signal or modulations of $100 \mathrm{cps}$ or $1 \mathrm{kHz}$.

Both units individually were capable of producting a doppler effect audible signal from a bats wing flapping at a close distance of approx. $1 \mathrm{~m}$. However a considerable improvement in range and sensitivity was obtained by placing the horns of both transmitters in very close juxtaposition with the rectangular cavities in parallel. An acutely sensitive region was created along the paths of the joint beams. At distances of up to $20 \mathrm{~m}$ very small movements can be detected in certain materials, even through closed wooden doors.

Experiments with Pipistrellus pipistrellus have shown that the wing beats in a flying bat can be detected at up to $15 \mathrm{~m}$ against a stable background.

While an audible signal can be produced using the equipment, it can also be made to operate a relay by the slightest movement of very small targets.

Although the principal interest will be to compare the signals caused by the doppler shift in the wing beats and bodies of flying bats which are made audible through the equipment, there is no doubt that the device might be used to count bats flying through an opening.

Although at present mains operated, both manufacturers could convert their equipment for hattery operation. Further development work is expected to continue.

\section{USE OF INFRA RED MONOCULAR FOR WATCHING BATS}

Some species of bat found in Britain appear to be sensitive to light. Myotis nattereri will only emerge when it is quite dark. Nursing colonies of Rhinolophus ferrumequinum are disturbed by the light of an electric torch. These are cited as examples to show that the use of night vision equipment has undoubtedly a useful place in the study of bats.

A reasonably inexpensive device for watching bats by infra red illumination has been described by Bateman \& Killick (1969) who discovered that a piezo-electric gas igniter, manufactured by Brush 
Clevite Ltd., Southampton, Hants, would drive a Mullard 6929 Image Converter. They describe a simple circuit which includes a capacitor storage facility.

A home made unit was built using inexpensive optics and this has proved very useful for watch- ing bats in the dark. The resolution of the Mullard image converter tube is very good.

The light source used was a torch covered by a Kodak Infrared filter. The same filter, placed over a car headlight has been used in the field. The resolution on flying bats is not so good but it is excellent for watching nursing colonies.

\section{REFERENCES}

Bateman, D. A. \& D. E. Killick, 1969. A piezo-electric power supply for an infrared image converter tube. J. sci. Instruments, (2) 2.
PYE, J. D., 1968. Animal sonar in air. Ultrasonics, Jan. 1968.

WATSON, A., 1965. Observing the natural behavior of bats in fight. Stud. Speleol., 1 (2/3). 